\title{
The effects of indoor and outdoor air pollutants on workers' productivity in office building
}

\author{
Cristina Becchio ${ }^{1}$, Marta Carla Bottero ${ }^{2}$, Stefano Paolo Corgnati ${ }^{1}$, Federico Dell'Anna ${ }^{2}$, Valentina Fabi $^{1}$, Carola Lingua $^{1}$ \\ Leonardo Prendin ${ }^{3}$, and Micaela Ranieri ${ }^{3}$ \\ ${ }^{1}$ Department of Energy (DENERG), Politecnico di Torino, Corso Duca degli Abruzzi 24, 10129 Torino, Italy \\ ${ }^{2}$ Department of Regional and Urban Studies and Planning (DIST), Politecnico di Torino, Viale Mattioli 39, 10125 Torino, Italy \\ ${ }^{3}$ Rhoss S.p.A., Via Oltre Ferrovia, 33033 Codroipo (UD), Italy
}

\begin{abstract}
In the present-day society, people spend about $80 \%$ of their time inside buildings, and specifically $30-40 \%$ in workplaces. From this evidence, the indoor environmental quality needs to be investigated, and in particular, the possible sources of indoor-outdoor pollutants and their impact on the human health, comfort and productivity. First, through an examination of the indoor sources of pollution, the research analysed the main substances that affect indoor air quality in an office. Second, the pollution of external origin and its effects on the performance of employees were taken into consideration. Two scenarios were designed for a Heating Ventilation Air Conditioning (HVAC) system in an office building; one by the installation of a biocidal filter and the other by a traditional one. Two methods were applied to evaluate and compare those scenarios; the Cost Benefit Analysis and the Monte Carlo Simulation. From a financial point of view, the investment and management costs of the filters were considered. Instead, the annual benefits included increasing productivity and reducing days of absence from work due to illness. The results confirmed the energy and socioeconomic efficiency of the antibacterial filter; it can be considered a solution to achieve the best income.
\end{abstract}

\section{Introduction}

The Indoor Air Quality (IAQ) represents a crucial aspect for human well-being and performances. In recent years the interest in the issues related to IAQ increased, due to a greater awareness of the indoor pollutants' effects on health, well-being and productivity of the occupants who spend about $80 \%$ of their time inside buildings $(30-40 \%$ in workplaces). Furthermore, the revised Energy Performance of Buildings Directive (EPBD) [1] promoted refurbishment and created the regulations to improve the Indoor Environmental Quality (IEQ) in order to optimize the well-being, health and productivity of occupants in indoor environments. For this reason, it has become necessary to take into account not only the energy consumption, but also the IEQ in the design of a comfortable building. Concerning in particular the workplaces, it is known that deteriorated indoor environmental quality may reduce performance at work until $100 \%$ loss of productivity when employee is absent from work [2]. Moreover, several studies suggest that better indoor air quality, in terms of low concentration of pollutants or high ventilation rates, can lead to a productivity improvement in a range between 3-7\% [3] and $10-15 \%$ [4]. The indoor air quality depends mainly on the concentration of indoor pollution, defined as the presence of chemical, biological or physical contaminants in the air of confined spaces [5]. Based on the different emission sources, indoor pollution can be divided into pollutants of outdoor origin (caused by vehicles or industries) and indoor origin (occupants, furniture, printers, building materials, Heating Ventilation Air Conditioning system).

This paper focuses on a specific research domain of IAQ and its impacts on productivity loss in workplaces. In detail, the research aims to demonstrate the economic benefits of replacing a traditional filter with a biocidal one in an air handling unit (AHU). In order to achieve this goal, first of all an investigation of the main outdoor pollutants that affect workers' performance in office building was developed. Subsequently, the effect of the installation of a biocidal filter on workers productivity were evaluated including in the economic analysis the benefits in terms of occupants' performance at work and sick leave days. The paper is structured in the following way. Section 2 shows the methodology of data collection deriving from the investigation of the impact of ventilation, indoor air quality and Sick Building Syndrome (SBS) symptoms on worker productivity. This literature review allowed to identify the main pollutants of outdoor origin affecting productivity. Section 3 describes the analysis methods used for developing the investigation. Section 4 concerns the application to an office building and it focuses on the workers' productivity benefit estimation. Finally, the last section (Section 5) describes the results of the economic evaluation and the implementation of the model with a probabilistic approach and a deterministic sensitivity analysis.

\footnotetext{
${ }^{*}$ Corresponding author: cristina.becchio@polito.it
} 


\section{Methods}

The research starts from a state-of-the-art literature survey about the main pollutants of external origin, introduced into building environment through an HVAC system. The review was evolved by using a wide literature looking at papers, books and the main Standards. Attention was paid to the effects of pollutants on workers' productivity in workplaces. Starting from statistical data coming from the literature review, a Cost Of Illness approach was developed in order to calculate the benefits of a biocidal filter. Finally, the results obtained in the first phases were implemented in a Cost Benefit Analysis (CBA) framework to evaluate the incremental benefits of a biocidal filter installation in an office.

\subsection{Pollutants affecting productivity}

A lack of a direct correlation between the outdoor pollutants and their effects on worker performances has emerged from the literature review. First, the main pollutants present in the outdoor environment have been investigated; according to the UNI EN 13779:2008 [6] they are identified by sulfur dioxide $\left(\mathrm{SO}_{2}\right)$, nitrogen dioxide $\left(\mathrm{NO}_{2}\right)$, carbon dioxide $\left(\mathrm{CO}_{2}\right)$, ozone $\left(\mathrm{O}_{3}\right)$ and airborne particulate matter (PM). Second, the research focuses on the effects of indoor environment quality related to ventilation rate, indoor air quality and SBS symptoms in order to establish which pollutants, mentioned before, affect directly worker productivity. [2] describes that by increasing the ventilation rate there is a reduction effect on the concentration of pollutants in the air, and consequently the prevalence of Sick Building Syndrome (SBS) symptoms decreases by improving the air quality. Several studies established and supported the relationship between ventilation rate and relative performance; [7] shows that the performance of text typing improved by $1 \%$ for each doubling in outdoor air supply in the range between 3 and $301 / s$ per person. [8] presents an experiment in an office building in which short-term sick leave was reduced by $35 \%$ when the outdoor air flow increased from 12 to 24 1/s per person. Another experiment in a call-center shows an improvement of $6 \%$ in operator performance (in terms of reduction in average call time), when the air flow rate was increased from 2.5 to $25 \mathrm{l} / \mathrm{s}$ per person [9]. In addition, different studies report the effects of air quality on work performance (removal of old computers or carpets) [10, 11 ] and show that for each $10 \%$ reduction of dissatisfied people about the indoor environment, the work performance increase of $1.1 \%$. [12, 13] defined a relationship between the increase in temperature, the reduction in ventilation and the air quality with SBS symptoms; these latter (headache, nausea, vomiting, fatigue) cause distraction and affect work performance. Finally, [14] describes a survey conducted in an outdoor environment that allows to investigate the effects of pollutants present in the outside air (sulfur dioxide, nitrogen dioxide and PM) on the incidence of SBS symptoms among residents in Shanghai. From this literature review emerges that all the outdoor pollutants, mentioned in the Standard, should be taken into consideration for the analysis. Only ozone from the outdoor environment cannot be considered, due to its degradation caused by crossing through the air treatment unit.

\subsection{Cost Of IIIness}

The Cost Of Illness (COI) technique is usually used to evaluate the benefits generated in health care [15]. The aim of this methodology is to identify and measure the costs of a disease, including direct, indirect and intangible components. The direct costs consist in health-care costs related to specialist visits, haematological and serological tests, diagnostic control procedures, supportive drug therapies and hospitalizations. Indirect costs refer to productivity losses due to morbidity and mortality, borne by the individual affected. To calculate indirect costs, reference was made to the Human Capital Approach (HCA) [16]. Based on this approach, the loss of productivity is calculated for the period between the income of the disease and the return to work activity. Lastly, intangible costs are associated to psychosocial effects. To estimate these impacts in a monetary term, approaches based on revealed preferences techniques are used. In the present research, we focused only on the evaluation of direct and indirect costs, overlooking intangible effects.

\subsection{CBA-based scenarios analysis}

A scenarios analysis based on Cost Benefit Analysis (CBA) approach is proposed to identify the incremental benefit of biocidal filter installation [17]. The CBA is an analytical tool that is used in investment decisions in order to assess alternative projects from a social point of view. In theoretical terms, the CBA combines financial approach based on Life Cycle Cost (LCC) method to economic dimension, introducing positive and negative externalities in the assessment. Summarising, the CBA method includes 5 steps: 1) identification of costs and benefits of the alternative projects; 2) estimation of the monetary values of costs and benefits; 3) construction of the cash flow; 4) definition of the discount rate; 5) calculation of the performance indicators. In this study, the Benefit/Cost ratio $(\mathrm{B} / \mathrm{C})$ is chosen to present the results. It consists in the relationship between discounted benefits flow and discounted costs flow, as shown in the formula (1):

$$
\frac{B}{C}=\frac{\sum_{t=1}^{t=n} \frac{B_{t}}{(1+r)^{t}}}{\sum_{t=1}^{t=n} \frac{C_{t}}{(1+r)^{t}}}
$$

where $n$ is the analytic horizon, $t$ represents the cash flow period, $B_{\mathrm{t}}$ is the cash flow of benefits, $C_{t}$ is the cash flow of costs, and $r$ is the discount rate. According to this evaluation criterion, a project is preferred to others based on the value of the ratio of benefits and discounted costs that must be greater than one. To consider the uncertainty of data embedded in the assessment model, a Monte Carlo simulation that performs risk analysis by constructing 
models of possible results by replacing a range of doubtful values on a probability distribution was made.

\section{Relation between IAQ and productivity}

\subsection{Filtering capacity}

The main difference between traditional filter and biocidal one is that the first is ineffective against gaseous substances. Instead, the biocidal air filtration can remove $5 \%$ more of airborne particulate matter, $1 \%$ of $\mathrm{CO}_{2}, 5 \%$ of $\mathrm{NO}_{2}$ until $20 \%$ of $\mathrm{SO}_{2}$. The present research considered that biocidal filter has a filtering capacity, related to pollutants of external origin, from $1 \%$ to $20 \%$ more than a traditional filter. Because of this assumption, a traditional filter, in order to achieve the same filtering effect of a biocidal one, requires an increase in the outdoor air-flow supply. The figure above shows two indoor environments respectively characterized by the installation of the traditional filter (Fig. 1a) and the antibacterial one (Fig. 1b). If the same concentration of pollutants $\left(\dot{\mathrm{C}}_{\mathrm{a}}\right)$, and of contaminants from human activity (i) must to be maintained in the indoor environment, the air flow rate ( $\dot{\mathrm{m}}^{\prime}$ and $\dot{\mathrm{m}}$ ") changes in the two different conditions according to the following relation (2):

$$
\dot{\mathrm{C}}_{\mathrm{a}} \text { is fixed } \Rightarrow \dot{\mathrm{m}}^{\prime \prime}<\dot{\mathrm{m}}^{\prime}
$$

where $\dot{\mathrm{C}}_{\mathrm{a}}$ is the indoor pollutants concentration, $\dot{\mathrm{m}}$ ' and $\dot{\mathrm{m}}$ " represent respectively the ventilation rate of the traditional and the biocidal filter.
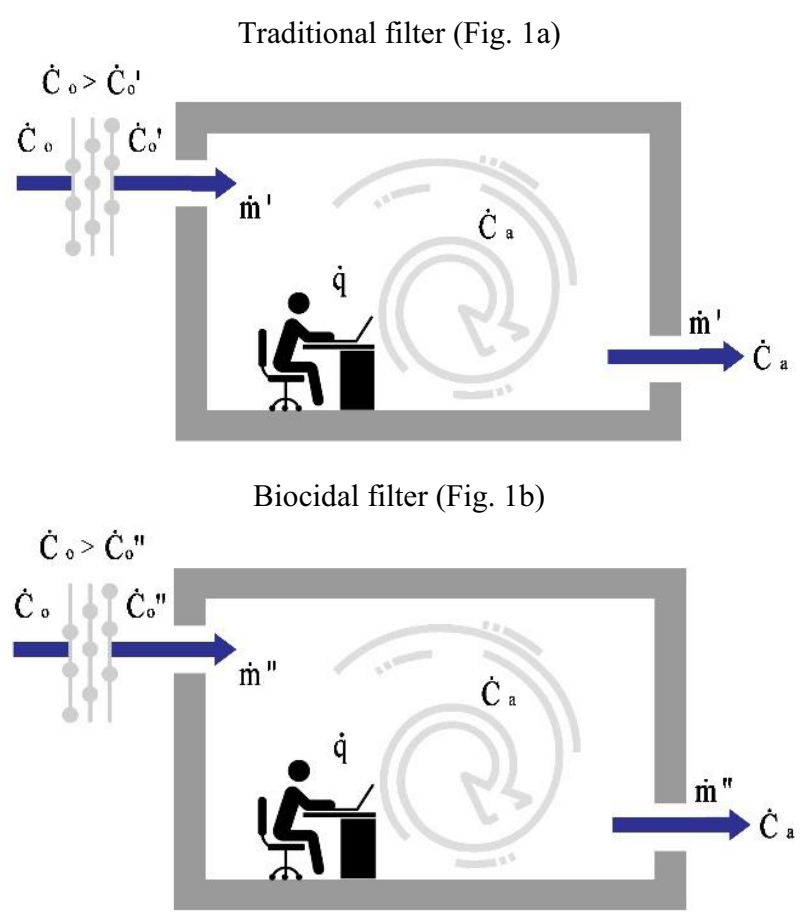

Fig. 1. Variation of outdoor air flow in order to maintain a fixed pollutants indoor concentration $\left(\dot{\mathrm{C}}_{\mathrm{a}}\right)$ comparing two different environments: an office with a traditional filter (a) and one with a biocidal filter (b).

\subsection{Workers' productivity benefits}

The parameters taken into consideration for the evaluation of the benefits reachable thanks to the installation of the biocidal filter in an office building refer to work performance and absence due to illness. These effects are included in the economic analysis and translated into monetary terms. To calculate the improvement in productivity we calculate how much the condition guaranteed by biocidal filter differs from that provided by the traditional one, according to minimum ventilation requirements (11 1/s per person). To calculate sickness absence, reference was made to the approach of the Human Capital Approach (HCA) [16], which estimates the days of work lost in relation to the average daily salary.

\subsubsection{Loss of productivity}

We have assumed that air quality is the only parameter that varies the work performance of the employees. The relationship between indoor air quality and work performance for the traditional filter (dashed line) and for the biocide filter (grey area) is shown in Figure 2.

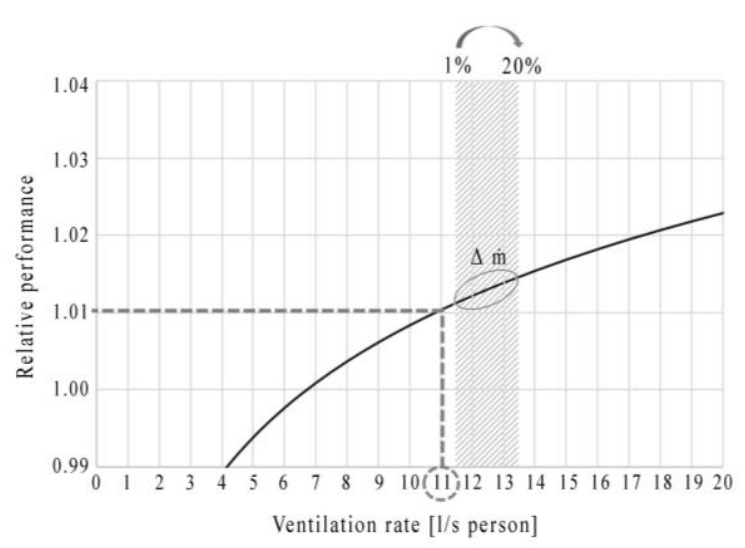

Fig. 2. Working performance in relation to the air flow.

The graph shows the relative performance on the $y$-axis, while on the $\mathrm{x}$-axis the ventilation flow rate $1 / \mathrm{s}$ per person. The curve represents the quantitative relationship between these two parameters, indicating an increase in work performance by increasing the air flow rate. The relation was calculated using formula (3):

$$
\begin{aligned}
R P_{v}= & \left(5.56 \times 10^{-8}\right) \times v^{3}-\left(1.48 \times 10^{-5}\right) \times v^{2}+ \\
& \left(1.49 \times 10^{-3}\right) \times v+0.983
\end{aligned}
$$

where $R P_{v}$ is the relative performance and $v$ is the ventilation rate ( $1 / \mathrm{s}$ per person). The equation (3) derived from the results of the statistical meta-analysis performed by Seppanen et al. [18] on the relationship between ventilation and work performance in working spaces. Figure 2 illustrates how office work performance varies with ventilation rate. Substantial growth occurs in the first part and then becomes almost constant at higher ventilation flow rates. The average performance increases 
by approximately $1 \%$ for $5 \mathrm{l} / \mathrm{s}$ per person increase in ventilation rate. At higher ventilation rates, the average performance increase is smaller, approximately $0.3 \%$ per $5 \mathrm{l} / \mathrm{s}$ per person increase in ventilation rate.

The increase in productivity was predicted using the relationship above that shows an increase in performance by higher ventilation rate. The benefits of increased productivity was explained into monetary terms, as annual revenue, considering the labour cost based on the average salary of employee.

\subsubsection{Direct and indirect avoided costs}

The effect of using the biocidal filter is reflected in an increase of workers' productivity in terms of reduction in days off work due to illness and as reduction in costs incurred due to a specific disease. This study includes both direct costs (costs of medical resources for the treatment of the disease) and indirect costs (loss of productivity). In this way, we adopted both company and the National Health Service (NHS) points of view. The adsorbent capacities of the biocidal filter are particularly indicated for the abatement of bacteria responsible for community pneumonia (CAP) and the CommunityAcquired Meningitis (CAM); Staphylococcus aureus and other Gram-negative bacteria. Pneumonia of non-hospital origin still represents an important event in terms of morbidity, since it affects an average of 5-11 people per year per 1000 inhabitants. In the case of the patient with suspected pneumonia, the severity of the clinical picture and the risk of complications must be assessed. Indeed, the decision to hospitalize the patient $(5 \% \div 51 \%$ of cases $)$ or to subject it to antibiotic treatment comes from medical evaluation. The meningitis occurrences are lower than those of pneumonia, recording 3-6 cases per year for every 100,000 inhabitants. For the estimation of direct and indirect costs, the Cost Of Illness (COI) method is applied (section 2.2). The direct costs for the hospitalization and antibiotic treatments are calculated following the formula (4):

$$
\begin{aligned}
& \text { Direct Costs }=\text { Medical treatment cost } \mathrm{x} \text { Abatement } \\
& \text { capacity } \mathrm{x} \text { Period spent } \mathrm{x} \text { Morbidity events }
\end{aligned}
$$

where the medical treatment cost is equal to the cost of health care, the abatement capacity is the biocidal filter capability to reduce pneumonia and meningitis bacteria, and the period spent reflects the worker time spent in the workplace, and morbidity events represent the occurrences of disease cases. The HCA plans to first calculate the possible cases of pneumonia in a specific case study, quantify cases of hospitalization, and calculate the potential benefits, following the formula (5):

$$
\begin{aligned}
& \text { Indirect Costs = Daily Salary } \mathrm{x} \text { Hospitalization days } \mathrm{x} \\
& \text { Period spent } \mathrm{x} \text { Morbidity events }
\end{aligned}
$$

where the Daily salary corresponds to the wage for different workers, Hospitalization days represent the average period of hospitalization to carry out the treatment.

\section{Application}

\subsection{Case study description}

The purpose of this study was to evaluate the effects of the installation of the biocidal filter on worker productivity, it was decided to select an office as case study for the application. The working environment is continuously influenced by different parameters related to the conformation of the work station, to the internal temperature, to visual and acoustic comfort, as evidenced by various studies [2]. In the design phase, little attention is given to determining a correlation between the quality of the internal environment and the productivity and performance of workers. A non-quality internal environment can reduce the work performance of employees. The first problems are related to the days of absence from work, due to the onset of diseases. This mainly affects the increase in the costs of the NHS and the social security system in economic terms. Other losses in economic terms derive from the reduction of work performance due to diseases related to the low quality of the indoor work environment. One of the parameters considered in this study is related to the effect of ventilation on worker performance. The hypotheses of the studies previously conducted start from the assumption that workers feel better thanks to good air quality and work in a proficient way. Given the above, the work environment is an excellent case to investigate the potential of the biocidal filter in terms of better air flow, compared to a traditional filter. Simulations for the calculation of costs and benefits for air quality improvement were run for a $400 \mathrm{~m}^{2}$ office buildings with 67 employees. Two alternative scenarios were designed;

- Scenario 1 with traditional filter; it corresponds to the installation of a traditional filter in the HVAC system of the office building.

- Scenario 2 with biocidal filter; the ventilation system is associated with an antibacterial filter which, in addition to reduce energy consumption, guarantees health benefits and an increased air flow rate.

\subsection{Evaluation of benefits}

Firstly, the productivity effect of biocidal filter was estimated according to the relationship between ventilation rate and work performance.

The analysis was performed in a comparative manner, evaluating how much the antibacterial filter allowed to obtain better indoor conditions in terms of indoor air quality. The increase in productivity was predicted using the relation showing an increase ranging from $1 \%$ to $20 \%$, in relation to the air flow. As shown in the graph in Figure 2 , the biocide filter could guarantee a better work performance thanks to an air flow greater than that required by the law (traditional filter), that ranging from 1.011 for an air flow of $11.1 \mathrm{l} / \mathrm{s}$, to 1.014 for $13.2 \mathrm{l} / \mathrm{s}$. This means that compared to a traditional filter, the work 
performance increases from $0.1 \%$ to $0.4 \%$, respectively. To convert the parameter linked to productivity into a unit that is homogeneous to that of the other costs, it is necessary to estimate the labour cost per worker per day. Labour costs can be obtained dividing the annual salary (gross salary) by annual working days. In this case study, an annual gross salary of $€ 27,500$ was assumed, and 220 working days per year. Therefore, an increase in productivity of $1 \%$ and $20 \%$ corresponds to an annual economic benefit per worker equal to $€ 27.50$ and $€$ 110.00 respectively.

Secondly, following the Cost Of Illness approach, the total direct and indirect costs caused by bacteria in workplace were assessed. By the health system, the direct costs consist of health-care including hospitalization and medical treatments. Following the formula (4) the direct costs related to CAP and CAM were calculated for the case study considered. The total expenses for the office building is equal to $€ 73.23$ per year.

The indirect costs considered the days of work lost due to admission to hospital treatment. The period of hospitalization for the pneumonia and meningitis has an average duration of about 10 days, which determine as many days of absence from work. For each diseased worker, the annual cost in terms of health avoided by biocidal filter is equal to $€ 9.21$.

\subsection{Financial-economic feasibility analysis}

The following phase of the research involved the financial and economic analysis in commercial sustainability terms of the antibacterial and traditional filter. The method used to verify the financial feasibility of the two supposed scenarios is the CBA. The European project evaluation guide [17] stresses that the positive and negative externalities generated by a project must be included in the feasibility analyses $[19,20]$. Two different evaluations were carried out, one for each scenario respectively. In accordance with the CBA methodology, the investment costs, annual operating costs (related to energy consumptions), annual replacement and disposal costs for the two filters were calculated. To comply with the limits set by the European Standard EN 15259:2007 [21], a large traditional filter is required. While, the medium size antibacterial filter is sufficient to guarantee regulatory limits. Each filter size requires an air handling unit of the same size that allows the installation of the filter; a larger AHU is required for the traditional filter. This implies a difference in the initial investment cost related to the purchase of the AHU, equal to $€ 833$. The annual energy costs for the traditional filter vary depending on the range of productivity benefits reached from installing the antibacterial filter $(1 \div 20 \%)$. A difference in the installation cost for the two filters occurs because is necessary to install an AHU of appropriate dimensions according to the size of the filter. Following the LCC method, it is therefore necessary to include in the valuation the residual value (RV) of the AHU component which at the end of the calculation period have not exhausted their usefulness. In detail, RV was calculated for the Scenario 1 that includes the traditional filter, as follow (6):

$$
R V=\left[1-\frac{D_{i}}{L_{e}}\right] \times C_{i}
$$

where $D_{i}$ is the period considered in the analysis, $L_{e}$ represents the economic life of the component, $C_{i}$ is the initial cost. Economic life corresponds to the period within which the component fulfils the functional performance, and a period of 15 years has been assumed for the AHU. On the benefits side, improvements in productivity and health were calculated, in terms of avoided costs. Once costs and benefits were identified, the following steps consisted in their quantification and monetization (Table 1).

Table 1. Costs and benefits data input.

\begin{tabular}{|l|c|c|}
\cline { 2 - 3 } \multicolumn{1}{c|}{} & $\begin{array}{c}\text { Scenario 1 } \\
\text { Traditional filter } \\
\text { (large size) }\end{array}$ & $\begin{array}{c}\text { Scenario 2 } \\
\text { Biocidal filter } \\
\text { (medium size) }\end{array}$ \\
\hline Costs & $913 € *$ & $150 €$ \\
\hline Investment & $\begin{array}{c}242.4 \div 292.8 \\
€ / \text { year }\end{array}$ & $156 € /$ year \\
\hline Energy & $4 € /$ year & $4 € /$ year \\
\hline Disposal & $40 € /$ year & $40 € /$ year \\
\hline Replacement & $277.66 €$ & $4,606.25 € /$ year \\
\hline Benefits & - & $9.09 € /$ year \\
\hline Residual value & - & \multicolumn{1}{|c|}{} \\
\hline $\begin{array}{l}\text { Worker } \\
\text { Productivity }\end{array}$ & $\begin{array}{l}|c| \\
\text { Health (indirect } \\
\text { costs) }\end{array}$ &
\end{tabular}

*The investment costs of the traditional filter include the unit cost of the large filter ( $€ 80$ ) plus the delta between a medium and a large air handling unit cost $(€ 833)$

Considering a calculation period of 10 years and a discount rate equal to $2 \%$, all annual costs and benefits were discounted and summed up separately.

\section{Results and discussion}

Monte Carlo simulations were combined with the CBA to calculate the results in a probabilistic way. A triangular distribution for the main uncertain parameters was assumed considering the minimum, the average and the maximum value as references. Furthermore, 200 independent scenarios were generated according to a $95 \%$ confidence interval. Figure 3 presents the variation of $\mathrm{B} / \mathrm{C}$ ratio according to the variation of the variable values for the Scenario 2. On the $\mathrm{x}$-axis the value of $\mathrm{B} / \mathrm{C}$ is shown, while on the $\mathrm{y}$-axis the probability is indicated. Table 2 shows the results obtained from Monte Carlo simulation. 
Table 2. Monte Carlo simulation results.

\begin{tabular}{|c|c|c|}
\cline { 2 - 3 } \multicolumn{1}{c|}{} & $\begin{array}{c}\text { B/C minimum } \\
\text { value }\end{array}$ & $\begin{array}{c}\text { B/C maximum } \\
\text { value }\end{array}$ \\
\hline $\begin{array}{c}\text { Scenario 1 } \\
\text { Traditional filter } \\
\text { (large size) }\end{array}$ & 0.05 & 0.06 \\
\hline $\begin{array}{c}\text { Scenario 2 } \\
\text { Biocidal filter } \\
\text { (medium size) }\end{array}$ & 13.13 & 30.99 \\
\hline
\end{tabular}

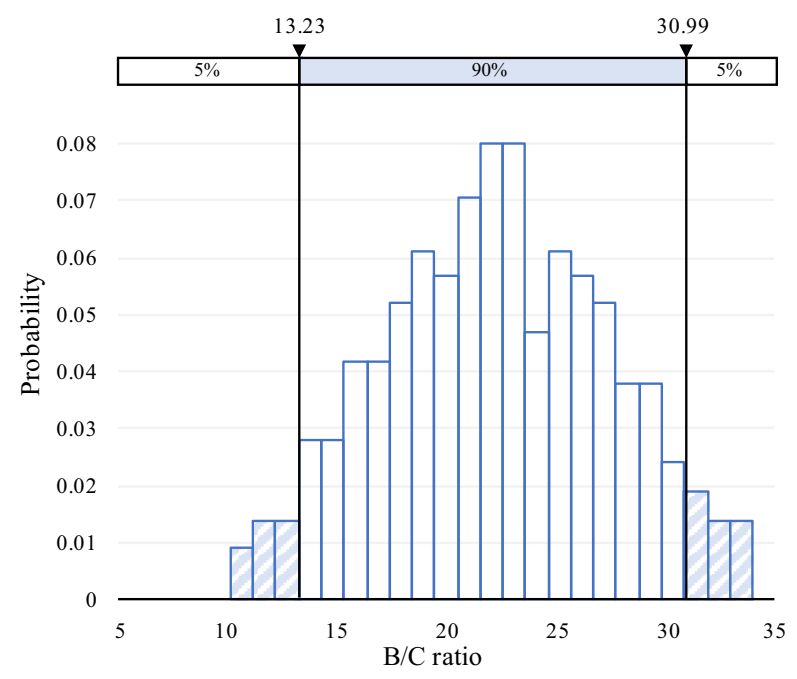

Fig. 3. Monte Carlo simulation for the Scenario 2.

The results shown the goodness of the installations of the antibacterial filter in the work environment. The biocidal filter is remarkably robust from the point of view of the positive economic impact on the financial statements, with a positive benefit even in cases where the minimum reference values are considered. From the point of view of economic and financial sustainability for the promoter, the installation of the antibacterial filter is advantageous. Once the uncertainty linked to some parameters identified by the Monte Carlo simulation has been eliminated, the CBA methodology requires a series of sensitivity analyses to validate the solidity of the results against specific uncertainties. We proceeded to evaluate the stability of the proposed solution by a deterministic "what-if" analysis of specific parameters identified in literature; in particular, the productivity and the health benefit (variation of $\pm 5 \%, \pm 10 \%$ ) that affect Scenario 2 is examined. Moreover, the variation of the cost of labour parameter allows to explore various working situations, where different professional figures with different professional level and therefore annual salary exist. In Table 3, the results related to the sensitivity analyses on the variation of the parameters for the Scenario 2 are shown considering the average values of the reference parameters.
Table 3. Deterministic sensitivity analysis.

\begin{tabular}{|c|c|c|}
\cline { 2 - 3 } \multicolumn{1}{c|}{} & $\begin{array}{c}\text { B/C value for } \\
\text { productivity variation }\end{array}$ & $\begin{array}{c}\text { B/C value for health } \\
\text { benefit variation }\end{array}$ \\
\hline$-10 \%$ & 19.637 & 22.157 \\
\hline$-5 \%$ & 20.726 & 22.159 \\
\hline $0 \%$ & 22.160 & 22.160 \\
\hline$+5 \%$ & 22.903 & 22.164 \\
\hline$+10 \%$ & 23.992 & 22.188 \\
\hline
\end{tabular}

In summary, in light of the evidences emerging from the sensitivity analysis, it can be seen that Scenario 2 is robust from the point of view of economic profitability and it is always preferable to Scenario 1 . The $\mathrm{B} / \mathrm{C}$ ratio assumes a maximum variation due to the change in the productivity value assuming a minimum of 19.637 to a maximum of 23.992. In this sense, this variable is crucial for the overall process and should be carefully monitored in the evaluation.

\section{Conclusions and future perspectives}

The application proposed in this study shows how the installation of an innovative antibacterial filter allows to improve the quality of the air through the biocidal function and the molecular filtration power. The proposed integrated methodology includes a financial and economic assessment in order to determine the net benefit generated by the installation of this innovative filter compared to a traditional one. For this reason, two scenarios were designed for a HVAC system for an office building. A CBA was set up to aggregate costs and economic benefits and compare the two scenarios. From a financial point of view, the investment and management costs (energy, replacement and disposal) were considered $[22,23]$. Instead, the annual benefits include increasing productivity and reducing days of absence from work due to illness [24]. The biocidal filter, thanks to its ability to remove bacteria and gaseous substances confirms its energy and economic efficiency. The antibacterial filter can be considered a solution to achieve the best income. However, the proposed method has limitations. The data used derive from literary sources. No real simulations were developed to take data. Furthermore, other externalities are not taken into consideration in this study. Among the economic benefits not considered we can identify the environmental impacts resulting from a reduction in energy consumption, the lower costs of staff turnover for the employer, the willingness to pay employees for not suffering from certain discomforts $[25$, 26].

\section{References}


1. Directive 2018/844/EU of The European Parliament and of the Council of 30 May 2018 amending Directive 2010/31/EU on the energy performance of buildings and the directive 2012/27/EU on energy efficiency (2018)

2. P. Wargocki, O. Seppänen, J. Andersson, A. Boerstra, D. Clements-Croome, K. Fitzner, S.O. Hanssen, Rehva Guidebook, 6 (2006)

3. P. Wargocki, Ph.D. Thesis, Technical University of Denmark (1998)

4. D. J. Clements-Croome, B. Li, Proceedings of Healthy Buildings 2000, 1, 629-634 (2000)

5. OECD, OECD Regulatori Policy Outlook 2018, (OECD Publishing, Paris, 2018)

6. UNI EN 13779. Ventilazione degli edifici non residenziali. Requisiti di prestazione per i sistemi di ventilazione e di climatizzazione (2008)

7. P. Wargocki, D.P. Wyon, J. Sundell, G. Clausen, P.O. Fanger, Indoor Air, 10, 222-36 (2000)

8. K. Milton, P. Glenross, M. Walters, Int. J. Indoor Air Qual. Clim., 10, 211-221(2000)

9. P. Wargocki, D.P. Wyon, P.O Fanger, Indoor Air, 14, 7-16 (2004)

10. Z. Bako-Biro, P. Wargocki, C.J. Weschler, P.O. Fanger, Indoor Air, 14, 178-87 (2004)

11. P. Wargocki, D.P. Wyon, Y.K. Baik, G. Clausen, P.O. Fanger, Indoor Air, 9, 165-79 (1999)

12. R. Niemelä, O. Seppänen, K. Reijula, Am. J. Ind. Med., 49, 819-25 (2004)

13. K.W. Tham, H.C. Willem, Proceedings of RoomVent 2004 Conference, (2004)

14. C. Sun, J. Zhang, Y. Guo, Q. Fu, W. Liu, J. Pan, Y. Huang, Z. Zou, C. Huang, Energ. Buildings, 174, 68-76 (2018)

15. T. Jefferson, M. Mugford, V. Demicheli, Elementary economic evaluation in health care (BMJ Books, London, 2000)

16. J. Broome, Economica, 52, 281-294 (1985)

17. European Commission, Guide to Cost-Benefit Analysis of Investment Projects: Structural Funds, Cohesion Fund and Instrument for Pre-Accession, Directorate-General for Regional Policy, (2014)

18. O. Seppänen, W.J. Fisk, Q.H. Lei, Indoor Air, 16(1), 28-36 (2006)

19. M. Bottero, M. Bravi, F. Dell'Anna, G. Mondini, Valori e Valutazioni, 21, 27-40 (2018)

20. C. Becchio, M.C. Bottero, S.P. Corgnati, F. Dell'Anna, Land Use Policy, 78, 803-817 (2018)

21. EN 15686-5. Buildings and constructed assets, Service Life planning. Part 5: Life-cycle costing (2008)

22. V. Barthelmes, C. Becchio, M.C. Bottero, S.P. Corgnati, Valori e Valutazioni, 16, 61-76 (2016)

23. M.C. Bottero, C. D'Alpaos, F. Dell'Anna, New Metropolitan Prospectives (Springer International Publishing, Cham, 2018)

24. C. Becchio, M. Bertoncini, A. Boggio, M. Bottero, S. Corgnati, F. Dell'Anna, New Metropolitan Prospectives (Springer International Publishing, Cham, 2018)

25. C. Becchio, M. Bottero, S. Corgnati, F. Dell'Anna, Smart and Sustainable Planning for Cities and
Regions (Springer International Publishing, Cham, 2018)

26. T. Buso, F. Dell'Anna, C. Becchio, M. C. Bottero, S. P. Corgnati, Energy Res. Soc. Sci., 32, 94-111 (2017) 